\title{
GAMBARAN FAKTOR INTERNAL DAN EKSTERNAL PELAKSANAAN INISIASI MENYUSU DINI (IMD) DI SALAH SATU PUSKESMAS KABUPATEN BANDUNG PERIODE MARET-APRIL 2019
}

\author{
Dewi Nurlaela Sari', Tika Vivi Ambarwati ${ }^{2}$ \\ ${ }^{1,2)}$ Program Studi D3 Kebidanan Fakultas Ilmu Kesehatan Universitas Bhakti Kencana \\ dewi.nurlaela@bku.ac.id
}

\begin{abstract}
ABSTRAK
Inisiasi Menyusu Dini (IMD) merupakan langkah awal keberhasilan pencapaian ASI Eksklusif. Permasalahan yang terjadi di lapangan IMD tidak dimanfaatkan dengan baik. Faktor ibu, bayi dan lingkungan dapat berperan dalam pelaksanaan IMD tersebut. Penelitian ini dilakukan untuk mengetahui gambaran faktor internal dan eksternal pelaksanaan IMD di Puskesmas Rancaekek Kabupaten Bandung Tahun 2019. Metode penelitian ini menggunakan metode deskriptif. Populasi dalam penelitian adalah ibu bersalin normal, sampel diambil dengan cara purposive sampling dengan jumlaj 39 responden. Analisis data menggunakan Analisis univariat dalam bentuk distribusi frekuensi. Hasil penelitian didapatkan bahwa pengetahuan, pendidikan dan sikap responden merupakan faktor internal yang memengaruhi terlaksanaya IMD. Adapun yang menjadi faktor eksternal pelaksanaan IMD yaitu peran keluarga dan dukungan dari petugas kesehatan. Simpulan dari penelitian ini yaitu pengetahuan, pendidikan, sikap, peran keluarga dan dukungan petugas kesehatan merupakan faktor yang berperan dalam pelaksaanan IMD. IMD diharapkan dapat dijadikan Standar Operasional Prosedur (SOP) dalam asuhan kebidanan.
\end{abstract}

Kata kunci : faktor eksternal, faktor internal, IMD

\begin{abstract}
First breast milk (IMD) is the first step to the works of achieving Exclusive ASI. Problems that occur in the field of IMD are not utilized properly where it is influenced by several factors both from mother, baby or the environment. For this reason, this research was conducted to determine the description of internal and external factors in implementing IMD in the Rancaekek Health Center in Bandung Regency in 2019. This research method uses the descriptive method. The population in the study were normal maternity mothers, the sampling technique was purposive sampling. Representation numbered 39 people. Data analysis was performed Univariate analysis in provided with frequency distributions. An knowledge, education, and attitudes were internal factors that influenced the implementation of IMD. While the external factors for implementing IMD are supporting from anyone, both families or midwives. Conclusions for the study are knowledge, education, attitudes, family roles and support of health workers are factors that play a role in the implementation of IMD. It is expected that IMD can be used as a Standard Operating Procedure (SOP) in midwifery care.
\end{abstract}

Keywords: external factors, IMD, internal factors 


\section{PENDAHULUAN}

Indikator peningkatan derajat kesehatan dapat dilihat dari penurunan Angka Kematian Bayi (AKB). Di Indonesia, AKB telah mengalami penurunan dari 34 per 1.000 kelahiran hidup di tahun 2007 menjadi 31 di tahun 2011. Sustainable Development Goals (SDGs), khususnya pada tujuan ketiga dengan terget utama menurunkan angka kematian neonatus sebesar 12 per 1.000 kelahiran hidup. Menurut Protocol Evidence Based yang baru diperbarui oleh organisasi kesehatan dunia dan organisasi PBB yang memberikan bantuan kemanusiaan dan dan perkembangan kesejahteraan jangka panjang kepada anak dan ibu di negara berkembang menyebutkan bahwa risiko kematian bayi antara 9-12 bulan meningkat $40 \%$ jika tidak mendapatkan ASI di 6 negara berkembang. Angka kematian tersebut akan meningkat menjadi $48 \%$ untuk bayi di bawah 2 bulan. Dengan Inisiasi Menyusui Dini (IMD) angka kematian bayi usia 28 hari dapat di kurangi sebanyak 22\% dan angka kematian balita sebanyak $8,8 \%$.

Pemberian ASI merupakan salah satu upaya yang dilakukan untuk mempercepat penurunan AKB. Adapun salah satu faktor yang memengaruhi keberlangsungan pemberian ASI adalah inisiasi menyusui dini. IMD merupakan program yang dikeluarkan oleh WHO dan UNICEF pada tahun 2007. IMD adalah permulaan kegiatan menyusu dalam satu jam pertema setelah bayi lahir, IMD juga dapat diartikan sebagai cara bayi menyusu satu jam pertama setelah lahir dengan usaha sendiri dengan kata lain menyusu bukan disusui. Cara bayi melakukan IMD ini dinamakan the breast crawl atau merangkak mencari payudara. Manfaat dari IMD yaitu apabila terjadi kontak kulit antara bayi dan ibu akan mengalirkan panas tubuh dari keduanya yang mencegah bayi hipotermi. Jilatan bayi di perut ibu pada saat mencari puting akan menelan bakteri lactobacillus yang sangat berguna untuk pencernaan bayi. Isapan bayi pada puting susu serta pijakan kaki bayi di perut bawah ibu akan menekan uterus dan merangsang kontraksi sehingga mengurangi perdarahan setelah melahirkan. Pemahan tentang inisiasi menyusui dini ini sangat diperlukan agar setiap penolong persalinan dan ibu melahirkan mau dan aktif dalam melaksanakan IMD.

Fakta di Indonesia hanya 4\% bayi yang disusui ibunya dalam waktu 1 jam pertama setelah dilahirkan. Berdasarkan target cakupan IMD dari pemerintah yaitu sebesar $80 \%$. Jawa Barat merupakan Provinsi dengan cakupan IMD yang rendah yaitu $48 \%$.

Berdasarkan data profil kesehatan Provinsi Jawa Barat Kabupaten Bandung merupakan salah satu kabupaten ke-5 terendah cakupan IMD. Diantaranya Jawa Tengah $(58,2 \%)$, Jawa Timur (57\%), Sumatera Barat (52,1\%), Jambi (51\%), dan Jawa Barat (48\%). Berdasarkan studi pendahuluan terdapat beberapa Puskesmas di wilayah Dinas Kesehatan Kabupaten Bandung yang memiliki cakupan IMD rendah, termasuk salah satunya Puskesmas Rancaekek (58\%).

Berdasarkan Roesli (2012) yang berjudul Inisiasi Menyusui Dini plus ASI Eksklusif disebutkan bahwa banyak faktor yang memengaruhi tercapainya IMD, yaitu faktor yang berasal dari dalam ataupun yang berasal dari luar ibu bersalin. Faktor dari dalam (internal) meliputi tingkat pengetahuan, pendidikan, sikap, dan kesehatan ibu. Adapun faktor dari luar (eksternal) meliputi kesehatan bayi, motivasi, peran keluarga, dan petugas penolong.

Hal tersebut didukung oleh penelitian Lestari (2014) menyatakan bahwa pelaksanaan kegagalan IMD ini salah satunya dapat dilihat dari faktor Internal seperti pengetahuan ibu, pendidikan ibu, keinginan ibu, dan sikap. Hal ini dibuktikan dengan hubungan tingkat pendidikan yang memiliki keeratan dibandingkan dengan 
variabel yang lain, yang merupakan faktor internal ibu yang sangat signifikan, sedangkan faktor eksternal dalam penelitian ini dipengaruhi oleh peran suami/keluarga dan bidan memberikan hasil signifikan.

\section{METODOLOGI}

Metode penelitian ini yaitu pendekatan deskriptif yakni penelitian yang menggambarkan suatu keadaan atau fenomena yang diteliti dengan sistematis dan akurat.. Instrumen penelitian berupa kuesioner dengan menggunakan data primer yaitu data yang diperoleh langsung dari responden. Populasi adalah ibu bersalin di Puskesmas Rancaekek periode Maret-April 2019. Sampel berjumlah 39 Ibu bersalin normal dengan teknik pengambilan sampling yaitu purposive sampling yakni peneliti menentukan pengambilan sampel dengan kriteria tertentu, yaitu ibu bersalin normal yang bersedia melakukan IMD.

\section{HASIL}

Berdasarkan penelitian yang telah dilakukan didapatkan hasil yaitu dari $50 \mathrm{ibu}$ bersalin didapatkan 39 orang ibu bersalin melakukan IMD dan 11 orang tidak melakukan IMD.

Tabel 1. Distribusi Frekuensi Gambaran

Faktor Internal IMD Berdasarkan

Pengetahuan di Puskesmas Rancaekek Kabupaten Bandung

\begin{tabular}{|c|c|c|}
\hline Pengetahuan & f & $\%$ \\
\hline Baik & 5 & 12,8 \\
\hline Cukup & 12 & 30,8 \\
\hline Kurang & 22 & 56,4 \\
\hline Total & 39 & 100 \\
\hline
\end{tabular}

Tabel 2. Distribusi Frekuensi Gambaran

Faktor Internal IMD Berdasarkan Tingkat

Pendidikan di Puskesmas Rancaekek Kabupaten Bandung

\begin{tabular}{lccc}
\hline & Pendidikan & f & \% \\
\hline SD & & 9 & 23,1 \\
SMP & & 17 & 43,6 \\
SMA & Total & 13 & 33,3 \\
\hline & & $\mathbf{3 9}$ & $\mathbf{1 0 0}$ \\
\hline
\end{tabular}

Tabel 3. Distribusi Frekuensi Gambaran

Faktor Internal IMD Berdasarkan Sikap

Ibu Bersalin di Puskesmas Rancaekek Kabupaten Bandung

\begin{tabular}{rcc}
\hline \multicolumn{1}{c}{ Sikap } & f & \% \\
\hline Mendukung & 17 & 43,6 \\
Tidak Mendukung & 22 & 56,4 \\
\hline Total & $\mathbf{3 9}$ & $\mathbf{1 0 0}$ \\
\hline
\end{tabular}

Tabel 4. Distribusi Frekuensi Gambaran

Faktor Eksternal IMD Berdasarkan

Peran Keluarga di Puskesmas Rancaekek Kabupaten Bandung

\begin{tabular}{ccc}
\hline \multicolumn{1}{c}{ Peran Keluarga } & f & \% \\
\hline Mendukung & 19 & 48,7 \\
Tidak mendukung & 20 & 51,3 \\
\hline \multicolumn{1}{c}{ Total } & $\mathbf{3 9}$ & $\mathbf{1 0 0}$ \\
\hline
\end{tabular}

Tabel 5. Distribusi Frekuensi Gambaran Faktor Eksternal IMD Berdasarkan Peran Petugas Penolong Persalinan di Puskesmas Rancaekek Kabupaten Bandung

\begin{tabular}{lcc}
\hline \multicolumn{1}{c}{ Petugas Penolong } & f & \% \\
\hline Mendukung & 23 & 59 \\
Tidak mendukung & 16 & 41 \\
\hline \multicolumn{1}{c}{ Total } & $\mathbf{3 9}$ & $\mathbf{1 0 0}$ \\
\hline
\end{tabular}

\section{PEMBAHASAN}

Berdasarkan tabel tersebut menunjukkan bahwa gambaran faktor internal dan eksternal dalam pelaksanaan IMD.

Gambaran faktor internal dari penelitian yaitu pengetahuan, pendidikan dan sikap ibu bersalin terhadap pelaksanaan IMD. Pengetahuan adalah hasil dari tahu melalui panca indera 
manusia terhadap suatu objek tertentu. Penelitian ini menunjukkan masih terdapat ibu bersalin yang memiliki pengetahuan kurang tentang IMD hasil wawancara menujukan ibu tidak memanfaatkan gadget nya untuk seraching informasi mengenai IMD, selain itu informasi mengenai IMD dirasakan kurang bahkan tidak diberikan oleh petugas kesehatan pada saat melakukan kunjungan pemeriksaan kehamilan.

Tingkat pendidikan, memengaruhi pengetahuan seseorang. Tingkat pendidikan yang tinggi diharapkan informasi yang diterima lebih dibandingkan dengan tingkat pendidikan yang lebih rendah. Pada penelitian ini didapatkan sebagian besar ibu bersalin dengan pendidikan menengah pertama (SMP). Ibu bersalin yang memiliki tingkat pendidikan yang lebih tinggi akan lebih menyadari pentingnya menyusu dini, membaca dan mencari informsi mengenai manfaat IMD sehingga lebih termotivasi untuk melakukannya. Selain itu tingkat pendidikan ibu bersalin yang tinggi akan memudahkan untuk menerima informasi baru sehingga pengetahuan yang dimiliki nya bertambah baik.

Pendidikan akan mempengaruhi pengetahuan sesorang dan pengetahuan ataupun pendidikan dapat membentuk sikap dari orang tersebut. Sikap adalah respon seseorang terhadap suatu rangsangan/stimulus tertentu. Selain itu dapat didefinisikan pula sebagai kesiapan menggapai yang bersifat positif atau negative terhadap suatu objek atau situasi secara konsisten. Pada penelitian ini sikap yang didapatkan dari ibu bersalin yaitu kurang mendukung terhadap pelaksanaan IMD.

Menurut Roesli (2014) pengalaman pribadi, pengaruh orang lain, kebudayaan, media massa dan faktor emosional merupakan faktor yang berperan dalam pembentukan sikap seseorang. Pada penelitian ini menggambarkan bahwa sebagian besar ibu tidak memiliki pengalaman dalam melakukan IMD dan merupakan hal yang baru saat bayi diletakan diatas perut ibu dengan skin to skin dibiarkan untuk mencari putting ibu sesuai usahanya. Memerlukan waktu sekitar 30-60 menit bagi bayi untuk berhasil menyusu secara dini dan mandiri, sebelumnya pemahaman ibu lebih tinggi terhadap IMD sehingga membentuk sikap yang mendukung. Selain pengalaman pribadi sikap seseorang dapat dipengaruhi pula oleh orang lain yang dalam hal ini faktor eksternal. Hal ini didukung oleh penelitian Ernawati (2015) yakni ibu multipara belum tentu memiliki sikap positif tentang IMD meskipun telah memiliki pengalaman sebelumnya tentang proses IMD apabila tidak mendapat dukungan dari keluarga.

Ibu bersalin yang mendapat dukungan keluarga akan memiliki motivasi lebih tinggi untuk melaksanakan IMD. Hal ini sesuai dengan penelitian yang dilakukan Shetty (2013) kepedulian ibu bersalin akan meningkat untuk melakukan IMD jika pada saat kehamilan mendapatkan dukungan penuh akan IMD dari suminya. Selain itu keluarga selain suami memiliki peranan penting juga dalam membentu sikap positifibu bersalin tentang IMD. Ibu bersalin akan memberikan ASI ekslusif jika mendapat dukungan penuh dari keluarga yang dimulai sejak pemberian IMD. Selain dukungan keluraga faktor eksternal lain yang digambarkan dalam penelitian ini yaitu faktor penolong persalinan. Pada penelitian ini lebih dari setengahnya petugas pertolongan persaliann mendukung terhadap pelaksanaan IMD. Pada tahun 2010 Kemkes mengungkapkan bahwa dalam asuhan persalinan persalinan normal, IMD termasuk asuhan pada bayi baru lahir yang harus dilaksanakan dengan seksama, hal tersebut didukung dengan peraturan pemerintah (PP) nomor 33 tahun 2012, bahwa setiap fasilitas kesehatan wajib menjalankan IMD. Dengan adanya PP tersebut memotivasi petugas kesehatan untuk melakukan upaya-upaya untuk tercapainya pelaksanaan IMD tersebut 
salah satunya dengan memberikan penkes tentang IMD dan mendukung terlaksanaanya IMD pada saat persalinan. Hal tersebut sejalan dengan penelitian (2013) yang mengungkapkan bahwa pelaksanaan IMD oleh ibu bersalin tidak terlepas dari dukungan klinisi dari pertugas kesehatan.

\section{SIMPULAN DAN SARAN}

Berdasarkan penelitian tersebut dapat terlihat bahwa berdasarkan gambaran faktor internal ibu bersalin memiliki pengetahuan kurang dan lebih dari setengahnya pendidikan ibu bersalin SMP, lebih dari setenghahnya sikap ibu bersalin kurang mendukung dalam pelaksanaan IMD.

Pengetahuan seseorang dipengaruhi oleh tingkat pendidikan, dengan tingkat pendidikan yang lebih tinggi diharapkan informasi yang diterima lebih dibandingkan dengan tingkat pendidikan yang lebih rendah. Pendidikan akan memengaruhi pengetahuan seseorang dan pengetahuan ataupun pendidikan dapat membentuk sikap dari orang tersebut. Pada penelitian ini sikap ibu bersalin kurang mendukung terhadap pelaksanaan IMD ditunjang oleh pengetahuan dan pendidikan yang kurang. Berdasarkan gambaran faktor eksternal didapatkan bahwa peran keluarga kurang mendukung dan peran bidan mendukung dari pelaksanaan IMD. Tercapainya pelaksanaan IMD tergantung pada faktor-faktor tersebut yang saling berkontribusi satu sama lain.

\section{DAFTAR PUSTAKA}

KeMenKes, R. I. Profil kesehatan Indonesia tahun 2015. Jakarta Kementeri Kesehat Republik Indonesia. 2016

Roesli, U. Panduan: inisiasi menyusu dini: plus asi eksklusif. Pustaka Bunda, 2012.

Dinas Kesehatan Provinsi Jawa Barat. Profil kesehatan provinsi Jawa Barat tahun 2012. Dinas Kesehatan Provinsi Jawa
Barat. Bandung: 2012.

Dinas Kesehatan Kabupaten Bandung. Data capaian KIA Kabupaten Bandung. 2018

Lestari, P. Beberapa Faktor yang Mempengaruhi Kegagalan Inisiasi Menyusu Dini (Studi Kasus di RSUD Kardinah Tegal). Medica Hospitalia: Journal of Clinical Medicine,2(3). 2014

Hastono. Analisis Data. Fakultas Kesehatan Masyarakat Universitas Indonesia; 2013.

Arikunto. Prosedur Penelitian Suatu Pendekatan Praktek. Jakarta: Rineka Cipta; 2010.

Maryunani, A. Inisiasi menyusui dini, ASI eksklusif dan manajemen laktasi. Jakarta: Trans Info Media, 2012.

Notoatmodjo, S. Ilmu perilaku kesehatan.Jakarta: Rineka Cipta, 2010

Azwar, S. (2017). Metode penelitian psikologi. Yogyakarta: Pustaka Pelajar

Ernawati, D., \& Anjarwati, A. Gambaran sikap ibu nifas tentang inisiasi menyusu dini. Jurnal Kebidanan dan Keperawatan Aisyiyah, 2018 Available from https:// ejournal.unisayogya.ac.id/ejournal/ index.php/jkk/article/view/543/225

Shetty, S. B., \& Shetty, K. KAP study of factors promoting breastfeeding in nursing mothers and pregnant women. Nitte University Journal of Health Science, 2013. 3(3). 43-44

Cox, K. N., Giglia, R. C., \& Binns, C. W. The influence of infant feeding attitudes on breastfeeding duration: evidence from a cohort study in rural Western Australia. International breastfeeding journal, 2015. 10(1), 25.

Hunter, T, et al. Breastfeeding initiation and duration in first-time mothers: exploring the impact of father involvement in the early post-partum period. Health promotion perspectives, 2014

Kementerian kesehatan. Panduan Pelayanan 
Kesehatan Bayi Baru Lahir Berbasis Perlidungan Anak. Jakarta: Direktorat Kesehatan Anak Khusus. 2010.
Kornides, Melanie; Panagiota Kitsantas. Evaluation of Breastfeeding promotion, Support and Knowledge of benefit or breastfeeding outcomes. $J$ Child Health Care. 2013. 17: 264-273. 